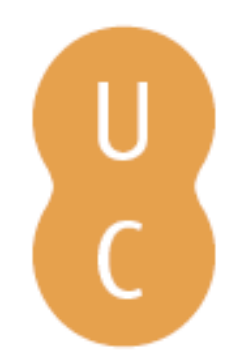

\title{
nombalina
}

\section{A viagem marítima como metáfora da criação literária: o exemplo paradigmático do humanista Aires Barbosa}

Autor(es): $\quad$ Pinho, Sebastião Tavares de

Publicado por: Imprensa da Universidade de Coimbra; Sapienza. Universitá di Roma

URL

persistente: URI:http://hdl.handle.net/10316.2/38772

DOI: $\quad$ DOI:http://dx.doi.org/10.14195/978-989-721-044-0_5

Accessed : $\quad$ 26-Apr-2023 08:59:48

A navegação consulta e descarregamento dos títulos inseridos nas Bibliotecas Digitais UC Digitalis, UC Pombalina e UC Impactum, pressupõem a aceitação plena e sem reservas dos Termos e Condições de Uso destas Bibliotecas Digitais, disponíveis em https://digitalis.uc.pt/pt-pt/termos.

Conforme exposto nos referidos Termos e Condições de Uso, o descarregamento de títulos de acesso restrito requer uma licença válida de autorização devendo o utilizador aceder ao(s) documento(s) a partir de um endereço de IP da instituição detentora da supramencionada licença.

Ao utilizador é apenas permitido o descarregamento para uso pessoal, pelo que o emprego do(s) título(s) descarregado(s) para outro fim, designadamente comercial, carece de autorização do respetivo autor ou editor da obra.

Na medida em que todas as obras da UC Digitalis se encontram protegidas pelo Código do Direito de Autor e Direitos Conexos e demais legislação aplicável, toda a cópia, parcial ou total, deste documento, nos casos em que é legalmente admitida, deverá conter ou fazer-se acompanhar por este aviso.

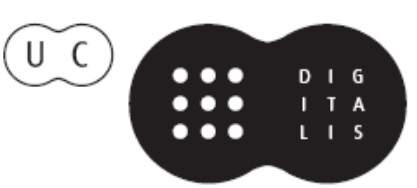




\section{Aires Barbosa na}

\section{Cosmopólis Renascentista}

Italo Pantani, Margarida Miranda \& Henrique Manso (coordenadores)

IMPRENSA DA UNIVERSIDADE DE COIMBRA

SAPIENZA. UNIVERSITÁ DI ROMA 


\title{
A Viagem Marítima como Metáfora da Criação Literária: o Exemplo Paradigmático do Humanista Aires Barbosa
}

\author{
Sebastião Tavares de Pinho \\ Universidade de Coimbra
}

- Então, ti Manel, como vai a vida?

- Cá vamos, meu amigo, ... tocando o barco.

"Tocando o barco" - uma expressão das mais recorrentes na linguagem popular e com raízes que se perdem na penumbra do tempo; uma metáfora herdada do campo da viagem náutica e de grande fortuna entre povos marinheiros, como eram os gregos e os latinos, de quem recebemos as bases da nossa cultura e, como eles, possuímos a mesma vocação marítima. Ela aparece com variadas aplicações, desde o sentido do decurso da vida, pessoal ou social e política, passando pela vivência amorosa expressa na obra dos poetas líricos, e sobretudo como imagem da gestação e criação literária. Mas sempre com o sentido geral de dificuldade, esforço e perigo, na luta genérica da experiência existencial, no desconcerto de amores e desamores, na utopia da governança e do poder, e no próprio desforço e nas dores de dar à luz uma obra escrita.

De tudo isto encontramos na história da literatura, desde as nossas fontes primordiais, sobretudo greco-latinas.

A metáfora da nau do Estado, por exemplo, que faz da vida política um percurso náutico e de quem governa um timoneiro, remonta ao séc. VII a. C. na voz do poeta Arquíloco (fr. 56 Diehl); tornou-se famosa mais tarde através dos poemas de Alceu (fr. 326 Lobel-Page); nela se baseou, quatro séculos depois, o poeta latino Horácio na sua alegoria da nau da república nos 20 versos da Ode I, 14, que se tornou famosa a ponto de, pouco depois, Quintiliano tê-la tomado como modelo, ao definir o conceito de alegoria. Mas, ainda na literatura grega, encontramos, por exemplo, na Antígona de Sófocles (séc. V a. C.) pelo menos quatro passos desta mesma metáfora náutica; e um caso de extrema expressividade é o da tragédia Sete contra Tebas, de Ésquilo, (séc. VI-V a. C.) em que Etéocles se apresenta como um almirante agarrado ao timão da cidade de Tebas metaforizada em navio acossado pela armada inimiga, e que os analistas chamam a "nau da maldição"1. Como metáfora da escrita, o comediógrafo Aristófanes (séc. V-IV a. C.) em Os Cavaleiros (vv. 541-544), toma a carreira do marujo a bordo como metáfora da vida e da carreira do dramaturgo ${ }^{2}$.

\footnotetext{
${ }^{1}$ Cf. Maria do Céu Zambujo Fialho. A Nau da Maldição. Estudos sobre Sete contra Tebas de Ésquilo. Coimbra: Minerva, 1996, p. 77 sgs.

${ }^{2}$ Cf. Maria de Fátima Sousa e Silva. Os Cavaleiros de Aristófanes. Introdução, versão do grego e notas. Coimbra: Centro de Estudos Clássicos e Humanísticos da Universidade de Coimbra, 1985, p. 70.
} 
$\mathrm{Na}$ literatura latina é abundantíssima a mesma metáfora nos vários campos em que ela funciona, entre os quais avulta o de elemento comparante da criação literária. É muito frequente ver um escritor a "enfunar as velas da oratória”, como se vê em Cícero (Tusculanas, IV, 5, 9), a largar as velas (vela dare) ao mar da produção poética, como em Virgílio nas Geórgicas (II, 3946), ou a recolher as velas (vela trahere) para terminar um excurso narrativo (ibidem, IV, 116-117). Ovídio é o poeta latino que porventura mais se serve da metáfora náutica para símbolo da escrita. Só na Arte de Amar, nos Tristia e nos Fastos, é possível encontrar mais de uma dezena de exemplos desse recurso. O mesmo se diga dos poetas Propércio e Estácio e mesmo dos prosadores Tito Lívio e Plínio-o-Moço.

De todos os autores portugueses em cuja obra encontrámos registada a metáfora náutica da criação literária, aquele que mais longa e expressamente a utilizou foi Aires Barbosa. Nascido por volta de 1475, em Esgueira, junto de Aveiro, estudou durante cerca de seis anos na Universidade de Florença, onde conheceu grandes mestres do humanismo italiano, como Hermolao Barbaro, Pico della Mirandola e Ângelo Policiano, de quem foi aluno assíduo, e onde teve por condiscípulo João de Médicis, futuro papa Leão X. Regressado a Portugal em 1495 como mestre graduado e especializado em línguas e literaturas clássicas, logo ingressou no corpo docente da Universidade de Salamanca, para aí se dedicar ao ensino da Retórica e das Humanidades. Tornou-se particularmente famoso como o primeiro professor da língua de Homero, pelo que ficou conhecido pela honrosa antonomásia de "Mestre Grego", como ainda hoje se pode ver na documentação universitária da época, e mereceu dos críticos modernos o apelido de "patriarca do helenismo ibérico". Depois de vinte e oito anos de trabalho letivo na cidade do Tormes, aí jubilou em 1523 e, a convite de D. João III, regressou a Portugal e passou a trabalhar no âmbito da corte como mestre dos irmãos do monarca português até 1530, ano em que pediu escusa dessas funções para passar os últimos dez anos de vida na sua terra natal.

Aires Barbosa, além de professor, foi também um excelente poeta latino, em que se notabilizou pelo poema Antimoria, de oposição ao "Elogio da Loucura" (Moriae Encomium) de Erasmo e deixou publicados mais de cem epigramas de tema variado. Mas as suas principais publicações têm caráter didático e filológico e são resultado de uma boa parte dos cursos que ele lecionou em Samalanca: um tratado sobre os verbos oblíquos (In verba M. Fabii, Quid quod et reliqua. Relectio de verbis obliquis, Salamanca, 1511); um compêndio de métrica, com o neologismo Epometria a servir de título (Relectio cui titulus Epometria, Salamanca, 1515); um volumoso comentário filológico ao poema Historia Apostolica de Arátor, que é a sua obra de maior vulto e importância (Aratoris Cardinalis Historia Apostolica cum Comentariis, Salamanca, 1516) e 
dois tratados conjuntos publicados em 1517, um sobre prosódia (Relectio cui titulus Prosodia) e outro sobre ortografia (Relectio cui titulus Orthographia).

Ora, grande parte destas obras exemplificam o frequente recurso de Aires Barbosa à referida metáfora náutica, com a aplicação de algumas das suas diversas funções estético-semânticas.

Uma delas é a que pretende simbolizar o comportamento do homem perante a complexidade da vida e a própria arte da existencialidade humana, que tantas vezes exige uma especial ginástica psicológica, que todos conhecemos. É nesse sentido que o poeta se dirige a si próprio, no epigrama 38 da coleção dos cinquenta publicados na tipografia dos monges de Santa Cruz de Coimbra, em 1536, quando se recolhera definitivamente à sua terra de Esgueira e aproveitara o remanso da jubilação para reunir e publicar as suas poesias inéditas ${ }^{3}$ :

\section{Ad se Paraenesis}

Rector ut in tumido puppim regit aequore gnarus

Quos uitet scopulos, quae loca tuta petat,

Frangit et hanc, buic cedit aquae, moderamine claui,

Infirmam tabulam per freta longa uehit,

Sic et, Ari, motus animi fluctusque tumentes

Nunc preme, nunc laxa, sub ratione tenens.

Indomitumque salum uitae uirtute gubernans,

Sic supera curas, ut maris ille minas.

Auto-exortação

[A NAU DA VIDA]

Tal como o piloto governa a popa no mar inchado, sabendo

Os escolhos de que deve fugir e os lugares seguros para onde rumar,

E, rompendo umas ondas e cedendo a outras com o governo do leme,

Conduz seu débil lenho através dos longos estreitos,

Assim também tu, Aires, ora aperta ora afrouxa a agitação

$\mathrm{E}$ os turbilhões entumecidos da alma, dominando-os com a razão.

$\mathrm{E}$, governando com denodo as indómitas vagas da vida,

Teus cuidados supera, tal como aquele as ameaças do mar.

Mas é sobretudo no sentido de criação e composição literária que a mesma metáfora da viagem náutica surge na obra do nosso humanista, como se vê logo no primeiro opúsculo pedagógico, publicado nos idos de junho de 1511, sobre

${ }^{3}$ Vd. Aires Barbosa. Arii Barvosae eiusdem Antimoria et nonnulla epigrammata. Coimbra: Mosteiro de Santa Cruz, 1536, fol. XXXX. 
os referidos verbos oblíquos, ou impessoais como diríamos hoje, do tipo oportet, licet, piget, etc., em que, ao concluir as páginas introdutórias sobre os motivos e a oportunidade desta obra, dá início à discussão do tema antecedendo-a das seguintes palavras, em que se mistura uma invocação às entidades divinas protetoras e inspiradoras da atividade da escrita com a linguagem metafórica da viagem marítima em que ela se desenvolve:

[...] Sed prius quidem te, Christe Theanthrope Liberator noster teque Deipara Virgo in huius actionis exordio inuoco; uos mibi clarissimi septentriones, ad quorum lumen in occiduum nostrae cymbae clauus dirigitur; uos mibi aeterni ignes, quorum fulgor nunquam occidit, semper lucet: Vos ego ueneror uestrum numen supplex imploro ${ }^{4}$.

"Mas, antes de mais, no exórdio desta demanda, quero invocar-vos, ó Cristo, Deus Humanado, Nosso Salvador, e a Vós, Virgem Mãe de Deus; a vós, que sois as minhas claríssimas estrelas do Norte, sob cuja luz o leme da minha barca se dirige para as águas do poente; a vós que sois meus eternos luzeiros, cujo fulgor nunca se põe e me alumia sem cessar; a Vós me dirijo e, suplicante, imploro o vosso divino poder."

É com esta invocação, de estrutura clássica mas de conteúdo cristão, numa simbiose, ou antes, numa substituição do maravilhoso pagão pelas referências de motivação cristã, como tantas vezes acontece na literatura do Renascimento, que Aires Barbosa desenvolve este seu tratado, e como se fosse numa viagem de barco para os lados do Ocidente (in occiduum), isto é, através do oceano Atlântico na perspetiva geográfica dum professor da vetusta universidade de Salamanca e num tempo áureo de descobertas ocidentais.

A mesma metáfora marítima aparece, em idênticas circunstâncias, no tratado da Ortografia do mesmo Aires Barbosa, publicado em dezembro de 1517, numa edição conjunta com o tratado da Prosódia, que o antecede. É no fim da introdução do tratado da Ortografia que o nosso humanista compõe um pequeno poema de catorze hexâmetros, que assume a forma de invocação, mais uma vez, às entidades do Criador, do Espírito Sagrado e sobretudo da Virgem Maria, no contexto metafórico de uma viagem náutica, desta feita de forma muito mais explícita e expressiva ${ }^{5}$ :

Sed sine te, quoniam mens nil, bone Conditor, audet

Nostra, nec exiguum, in montes mea lumina tollo,

\footnotetext{
${ }^{4} \mathrm{Vd}$. Aires Barbosa. In verba M. Fabii Quid? quod et reliqua. Relectio de verbis obliquis. Salamanca, 1511, fol. a ij v.

${ }^{5}$ Vd. Aires Barbosa. Relectio cui titulus Prosodia [et] Relectio cui titulus Orthographia, Eiusdem Arii B. nonnulla epigrammata. Salamanca, 1517 , fol. b vj v.
} 
Vnde mibi auxilium ueniat. Da Spiritus auram

(En totas illi uelorum pandimus alas)

Sancte, tuam, flatuque sinus implere secundo

Dignare, omnipotens. At tu, sacra sponsa Tonantis,

Cui flos cum tanto fructu contexitur, hoc est

Dulce decus matris cum uirginitatis honore

Vnica coniungens, nobis succurre, tuoque

Vultu tellurem, caelum, mare, cuncta serena.

Ipsa pia lege uela manu, uel lintea flabris

Pandito, uel clauum residens in puppe guberna.

Quidquid ages, sancto mea numine tuta sub isto

Nauis, et optatum portum, et sua litora tanget.

"Mas porque sem ti, meu bom Criador, a nossa mente

Nada ousa nem mesmo exíguo, ergo meus olhos para os montes

Donde me possa vir auxílio. Concedei-me, Espírito Sagrado,

Vossa aura (eis que lhe abrimos inteiramente as asas

Das nossas velas) e dignai-vos encher seu côncavo com o vosso

Favorável sopro, Deus omnipotente. E vós, sacra esposa do Tonante,

Cuja flor se entretece com tamanho fruto, isto é,

Vós que sois a única a juntar a doce glória de Mãe

Com a honra da virgindade, socorrei-nos e, com vosso

Vulto, a terra, o céu, o mar, a tudo serenai.

Recolhei com vossa mão piedosa as próprias velas, ou abri

aos ventos as telas de linho, ou, postada à popa, sede vós a timoneira.

Façais o que fizerdes, a minha nau, sob a tutela de vosso sagrado

Poder, há de surgir nas praias do porto desejado."

Mas o recurso mais desenvolvido à viagem marítima como expressão metafórica da criação e composição literária apresenta-se no longo Comentário feito por Aires Barbosa a Arátor, escritor dos séculos V-VI e cardeal do papa Vigílio, que figura entre os poetas cristãos continuadores dos cânones da poesia clássica e que compôs um poema de cerca de 2000 versos sobre o texto neotestamentário dos Atos dos Apóstolos, num estilo épico ao modo virgiliano. A obra divide-se em dois livros, sendo o primeiro dedicado aos feitos do apóstolo Pedro e o segundo aos atos de Paulo. O próprio conteúdo deste poema e as circunstâncias que levaram Barbosa a comentá-lo explicam o uso exaustivo daquela metáfora em que o autor envolveu o seu trabalho.

De facto, tratando-se de uma composição de estilo místico, frequentemente simbólico e de um acentuado hermetismo e por isso de difícil interpretação, Aires Barbosa entendeu que era um bom texto para objeto de comentário filológico segundo as novas técnicas das escolas renascentistas 
em que ele se formara, começando pela crítica textual seguida da hermenêutica e da crítica literária, segundo o mesmo processo de análise aplicado aos autores clássicos. Esse trabalho foi desenvolvido durante um curso letivo, por volta do ano académico 1512-1513. E, três anos depois, e por reiterada insistência dos alunos que o frequentaram e para avivar a memória destes e benefício dos que não tinham tido esse privilégio, o Mestre Grego decide publicá-lo. Ora, a consciência da particular dificuldade hermenêutica desta obra foi uma das razões que levaram o humanista a comparar essa tarefa a uma longa e penosa viagem pelo mar com todas as intempéries e perigos que a acompanham.

Logo à cabeça do prefácio do longo Comentário, Barbosa reconhece que a sua publicação servirá não só para reavivar a memória dos alunos, "mas também para benefício, a bem dizer, de todos e cada um dos estudiosos das belas-letras, que não ousam penetrar na própria obra de Arátor como se ela fosse num pélago profundo": sed etiam cunctis fere studiosis bonarum litterarum, qui ipsum Aratoris opus non audent tanquam profundum pelagus intrare ${ }^{6}$.

E para confirmar o caráter hermético do poema de Arátor e o particular esforço que o seu comentário exige e que tem demovido outros filólogos de ousarem fazê-lo, Barbosa não se coíbe de estabelecer o seu confronto com a poesia, bem mais fácil, de três poetas da mesma época e igualmente cristãos, todos nascidos na Hispânia, e cuja obra havia sido recentemente comentada por outros, designadamente pelo seu colega, António de Nebrija, com quem conviveu e manteve alguma mais ou menos delicada rivalidade. Diz Barbosa:

Cum enim per reliquorum Christianorum uatum poemata, quasi per stagna quaedam, facile nauigent et Prudentii, Sedulii, Iunenci carmina suis discipulis exponant, uelut in portu uelificantes, adire ad hunc timent, uel, si adeunt, loca proxima et oras primi litoris tantum legunt, altum metuentes, et a terra nusquam longius recedentes?.

"Com efeito, apesar de navegarem com facilidade pelos poemas dos restantes vates cristãos, como quem atravessa certas lagoas de águas mansas, e embora expliquem aos seus discípulos os poemas de Prudêncio, de Sedúlio, de Juvenco, como se fosse a velejar dentro de um porto, deste têm eles medo de se aproximar e, se o fazem, costeiam apenas os lugares próximos e a borda da beira-mar, receando o mar alto e sem se afastarem, em nenhum ponto, para mais longe

${ }^{6}$ Vd. Aires Barbosa. Aratoris Cardinalis Historia Apostolica cum Commentariis. Salamanca: Juan de Porris, 1516, fol. ii.

${ }^{7}$ Vd. ibidem; cf. José Henrique Manso, Comentário de Aires Barbosa à Historia Apostolica de Arátor (Textos Preliminares e Primeira Seç̧ão do Livro I). Estudo Introdutório, Fixação do Texto, Tradução e Notas. Coimbra: Faculdade de Letras, 2001, pp 72-73 [tese de mestrado, policopiada]. 
da terra."

E com esta linguagem comparativa começa Barbosa a sua longa metáfora náutica, que se desdobra ocupando toda a estrutura do prefácio e se renova e estende repetidas vezes ao longo da obra inteira, numa complexa cadeia de recursos alegóricos. Assim, depois de um longo discurso colocado na boca dos seus alunos com grande cópia de argumentos para convencerem o Mestre Grego a publicar estes comentários, Barbosa, cede ao seu pedido, mas recorda-lhes a multiplicidade de perigos que essa aventura implica, deste modo:

Equidem ista audiens quibus ego (liceat concedere uerbis) assentior, morigerari uobis et uolo et cupio. Verum neutiquam uos fugit qua mibi sit nauigandum, quales et quam turbulentos uentorum flatus in isto mari procelloso, quam graues fluctus tortuosi turbinis, quam difficiles scopulos, quam multa loca aduersa et Scyllaeis canibus et naufragio obnoxia sim transmissurus. Non uos praeterit quoties nobis sit, prius quam ad optatae quietis sinum prouehamur, desperandum, quoties incerta spe nautarum in morem, et uotis magis quam fiducia nauigantes, uagi instabilesque uenti aut nos deserentes moraturi sint, aut in aduersam tempestatem nitentes longe a proposito nobis cursu depulsuri, praesertim cum meae infirmitatis hand nescius, aut quibus rudentibus malum, aut quibus ancoris nauim muniam incertus sim. ${ }^{8}$

"Certamente que, ao ouvir essas razões, com as quais (valha a verdade) eu estou inteiramente de acordo, é minha vontade e desejo procurar agradar-vos. Mas vós não ignorais de modo nenhum por onde eu tenho que navegar, quais e quão ciclónicas tempestades de ventos nesse mar de procelas, quão pesadas vagas de um recurvo turbilhão, quão difíceis escolhos e quantos lugares adversos e sujeitos aos cães de Cila e a naufrágio eu terei que atravessar. Não vos passará despercebido quantas vezes entraremos em desespero antes de atingirmos a enseada da apetecida tranquilidade, quantas vezes, com a esperança incerta como os marinheiros e navegando mais pelo anseio que pela confiança, os ventos vagabundos e instáveis ou, abandonando-nos, hão de deixar-nos parados, ou, forçando-nos contra a tempestade iminente, hão de afastar-nos para longe da derrota por nós traçada, mormente quando, tendo eu plena consciência da minha debilidade, não tenho certeza nem com que amarras hei de segurar o mastro nem com que âncoras defenderei a nau."

Mas, apesar deste quadro negro que, em tempo poético, Aires Barbosa antevê, ele assume a tarefa da composição e publicação desta sua obra como um seu dever cívico, académico e mesmo religioso, e assim decide:

Haec ego et his plura, quae me, ut mox ostendam, ab huius turbulenti maris ingressu

\footnotetext{
${ }^{8}$ Vd. Aires Barbosa. Aratoris Cardinalis..., fol. ii; cf. Manso, op. cit., pp.74-77.
} 
auertebant, mibi posthabenda duxi, ut Deo meo aliquo officii genere obsequerer, et ei obsequendo, uobis, auditores suauissimi, commodarem. ${ }^{9}$

"A estes obstáculos e muitos mais, que, como em breve mostrarei, me demoviam de entrar neste mar turbulento, entendi ser meu dever pô-los de parte, a fim de me dedicar ao meu Deus com algum tipo de tarefa e, ao dedicar-me a Ele, me colocar, amabilíssimos ouvintes, também ao vosso serviço.”

Dada, porém, a sua assumida fraqueza, o humanista recorre ao poder divino para implorar um especial auxílio, a fim de encetar esta viagem de gestação literária, tendo por fundo sempre a mesma imagem marítima:

Sed quia nostra fragilis ac minus firma nauis tot periculis aduersi gurgitis impar est, tuae maiestatis opem ante omnia imploramus, ut extensa tibi spei nostrae uela contra instabiles uentorum flatus stabili flatu spiritus tui impleas, atque ita impactas de te pendenti nauigio ponti minas frangas tu ad tutissimum portum optati litoris ipsum prosequare. ${ }^{10}$

"Mas porque a nossa barca, frágil e de fraca resistência, não pode ombrear com tantos perigos do sorvedouro que tem pela frente, imploramos antes de tudo a ajuda da Vossa Majestade, para que, contra os inconstantes sopros dos ventos, Vos digneis, com o constante sopro do vosso espírito, encher as velas da nossa esperança, para Vós estendidas, e quebrar as ameaças do oceano lançadas contra uma navegação de Vós dependente, de modo a acompanhá-la até ao seguríssimo porto da praia apetecida.”

Aires Barbosa aceita, com humildade, que este seu plano possa estar votado ao fracasso, por não ser digno do favor da ajuda divina e, nesse caso, admite, em termos retóricos e talvez em certo tom de ironia, que isso até poderá dar ocasião a que outro mais talentoso o possa substituir nesta viagem náutica de composição literária, quando afirma:

At etiam aliquis forte excitabitur naufragio meo qui Deo carior, ingenio sublimior, doctrina locupletior, uices tanti operis excipiat, quique certa superni numinis spe confirmatus, utilem uerae litteraturae candidatis nauigationem transigat. ${ }^{11}$

"E até se sentirá porventura estimulado com o meu naufrágio alguém que, sendo mais caro a Deus, mais sublime em talento, mais rico em conhecimentos, continue na minha vez o encargo de tamanha obra, e que, confirmado pela firme esperança do poder superno, leve a bom termo esta navegação útil aos

\footnotetext{
${ }^{9}$ Vd. Aires Barbosa. Aratoris Cardinalis..., fol. ii; cf. Manso, op. cit., pp. 76-77.

${ }^{10} \mathrm{Vd}$. Aires Barbosa. Aratoris Cardinalis..., fol. ii; cf. Manso, op. cit., pp. 76-77.

${ }^{11}$ Vd. Aires Barbosa. Aratoris Cardinalis..., fol. ii; cf. Manso, op. cit., pp. 76-77.
} 
candidatos da verdadeira literatura.”

Entretanto, e apesar de tudo, o humanista termina este longo prefácio com a firme disposição de entrar nas ondas encapeladas da redação e publicação dos comentários ao poema de Arátor, esquecendo todos os seus detratores, simbolizados mais uma vez na referência mitológica dos monstruosos cães de Cila:

At quoniam oportet (quemadmodum sapientes praecipiunt) ut templis uestibula et aditus sic scriptis nostris principia proportine respondere, non euagabor iam amplius, sed uno uerbo colligam, in calce professus huius exordii, me, ut talentum Dei mei aliquo lucello augeam, bono animo et hosce marinos fuctus ingredi, et quoscumque Scyllaeos latratus contemnere. Addetur autem aliquid talento, si uobis, auditores, plurimum mea commentatio profuerit. ${ }^{12}$

"Mas, visto que (conforme prescrevem os sábios), do mesmo modo que acontece nos vestíbulos e nas entradas em relação aos templos, também no começo da nossa obra escrita é necessário respeitar uma correspondência proporcional, não me alongarei em mais divagações, e, ao apresentar-me na meta final deste exórdio, concluirei, numa só palavra, que, para fazer crescer com algum pequeno lucro o talento que Deus me concedeu, é com a melhor disposição que avanço para dentro destas vagas marinhas e desprezo toda a espécie de latidos de Cila."

E deste modo Aires Barbosa dá início ao longo e minucioso comentário ao Livro I do poema de Arátor, feito palavra a palavra, num total de cerca de 1.100 hexâmetros heroicos distribuídos por 25 secções, correspondentes a outros tantos episódios ou atos do apóstolo Pedro.

Chegado ao fim desta primeira parte, prepara-se para o comentário ao Livro II, que é antecedido de um prefácio próprio, dirigido, tal como no primeiro, "aos jovens estudantes das belas-letras" e que retoma e desenvolve a metáfora náutica iniciada no prefácio do Livro I, desta vez ainda em termos ainda mais eloquentes, agora que o autor já experimentou o peso e as dificuldades da laboriosa tarefa de escritor e comentarista. Assim fala Barbosa aos seus alunos:

Perfecto operis a nobis suscepti primo libro, auditores suauissimi, et iam maiori fere laboris Deo et nobis dedicati parte transacta, quam procul a terra nostra ratis processerit sentire incipimus. Dum enim e portu ea soluebatur et fidae stationis sinus oraeque primi litoris ante oculos erant, optima spe alebamur, et interdum in uicinam tellurem montesque propinquos nec dum euanescentes lumina reflectebamus, interdum in pelagus transmittendum spectantes, perinde quasi

\footnotetext{
${ }^{12}$ Vd. Aires Barbosa. Aratoris Cardinalis..., fol. iii vo; cf. Manso, op. cit., pp. 96-97.
} 
nobis sat firma atque instructa nauis esset, nec uela contrabere, nec remos inbibere curabamus. Mox aura sollicitante prouecti longius nec a tergo litus iam, nec a fronte portum conspicimus.

Certe nunc experti minas pelagi undique circumpositi, quid sibi illud Vergilii carmen uelit intellegimus: "Iam non amplius ulla occurrrit tellus, caelum undique et undique pontus", atque in alto turbatoque mari deprehensi nec retro ire sine dedecore, nec ultra tendere sine periculo possumus; adeoque fluctus adhuc emetiendi nobis occurrunt impediti ac difficiles (sunt enim uel emensis difficiliores) ut nunc demum nostrae temeritatis admoneamur, qui rate fragili tam uastum aequor tamque turbulentum intrauerimus. $^{13}$

"Concluído o primeiro livro da obra tomada a nosso cargo, amabilíssimos ouvintes, e quase terminada a maior parte do trabalho que a Deus e a vós dedicamos, começamos a dar-nos conta de para quão longe da terra avançou a nossa barca. $\mathrm{Na}$ verdade, enquanto ela zarpava do porto, e a enseada do fiel ancoradouro e as praias da beira-mar estavam diante dos nossos olhos, uma enorme expetativa nos alimentava, e umas vezes voltávamo-nos para trás olhando a terra vizinha e os montes próximos que ainda não haviam desaparecido da vista; outras vezes, contemplando o pélago que tínhamos de transpor, como se tivéssemos uma nau devidamente robusta e construída, não curávamos de recolher as velas nem de abrandar os remos. E em breve, impelidos para mais longe por uma forte brisa,já não enxergamos nem praia nas costas, nem porto à nossa frente.

Agora, ao experimentar as ameaças do pélago que nos cerca por todo o lado, é que entendemos o sentido daquele verso de Virgílio "Já não mais se avistava terra alguma, apenas céu de todo o lado, de todo o lado a extensão do mar”, e, surpreendidos no mar profundo e conturbado, não podemos voltar atrás sem desonra, nem prosseguir mais além sem perigo; e as vagas ainda por atravessar surgem-nos de tal modo intransponíveis e com tal dificuldade (são na verdade até mais difíceis do que aquelas já ultrapassadas), que só neste momento nos apercebemos da nossa temeridade, agora que entrámos neste tão vasto e tão turbulento espaço marítimo.”

Para lá das dificuldades objetivas e científicas inerentes à feitura de um livro - à fetura, isto é, à "gestação", ou "criação", como diria Lopo Serrão: "Ad Lectorem"14 - , sobretudo de uma obra de caráter eminentemente filológico como é esta do humanista Aires Barbosa, com todo o trabalho de pesquisa e análise, de heurística e hermenêutica que ele teve de resolver, acrescem os obstáculos e resistência dos seus opositores, invejosos e inimigos, que são, quase sempre, os amigos da mesma arte, e que residiam dentro da própria

${ }^{13}$ Vd. Aires Barbosa. Aratoris Cardinalis..., fol. cii - cii vo.

${ }^{14}$ Sebastião Tavares de Pinho. Lopo Serrão e o poema Da Velbice. Estudo introdutório, texto latino e aparato crítico, tradução e notas. Coimbra: Centro de Estudos Clássicos e Humanísticos da Universidade de Coimbra, 1987, p. 277. 
Universidade de Salamanca, como ele denunciou por escrito em um dos seus epigramas ${ }^{15}$.

Com efeito, desde que o humanista português integrou o corpo docente salmantino, empenhou-se no movimento de reforma pedagógica e científica na área das humanidades, com a defesa do estudo das línguas de acesso direto às bases da cultura universitária, a começar pela língua grega, praticamente desconhecida, e pelo incremento e maior rigor no domínio do latim, a língua de uso oficial mas que havia atingido níveis de degradação escandalosa. Acrescia, ainda, a necessidade de purificar os textos dos autores programáticos, nas várias disciplinas de todas as faculdades, mediante a aplicação de uma rigorosa crítica textual, para a purgação de toda a espécie de excrescências acumuladas ao longo dos séculos.

Esta luta de Aires Barbosa, de resto já antes iniciada por outros humanistas como António de Nebrija, causou a maior reação dos mestres conservadores do Estudo salmantino, sobretudo juristas, médicos, filósofos e teólogos. Desse combate contra "a barbárie universitária" - a expressão é dos dois humanistas dá conta o Mestre Grego em muitos dos seus epigramas latinos de cariz satírico. E é a tais opositores que ele agora se refere, usando da mesma linguagem alegórica da viagem marítima:

Verum enim uero haec quae paulo ante dixi nequaquam me tantum mouent, ceteraque quibus in alto nautae terrentur - crebri turbines, atrum caelum, globi fumigantes, latentes scopuli - quantum Scyllaei canes et maleficum genus piratarum, qui hoc ipsum quod nauigamus mare, latrociniis ex occulto inuadentes grauius infestant. Hi uel bonis nos spoliare nostris puppemque infirmam pessumdare, uel moram moliri nostraeque nauigationis cursum interpellare conabuntur. ${ }^{16}$

"Mas, em boa verdade, o que me inquieta não são, de modo algum, tanto estes perigos de que há pouco falei e os restantes com que os marinheiros são aterrorizados no alto mar - os sucessivos turbilhões, um céu de negro aterrador, os rolos de vagas fumegantes, os rochedos latentes -, como sobretudo os cães de Cila e a maléfica raça dos piratas, que, atacando às ocultas este mesmo mar que navegamos, o infestam com bem pesados latrocínios. Estes hão de tentar ou espoliar-nos de nossos bens e meter a fundo a nossa embarcação, ou tramar a demora e interromper a rota da nossa navegação."

Barbosa procura rebater todos os ataques dos seus adversários, "mas", diz ele, "os violentos corsários, repelidos dum lado, irão sacudir a nossa embarcação

${ }^{15} \mathrm{Vd}$. Aires Barbosa. Arii Barvosae eiusdem Antimoria et nonnulla epigrammata, fol. XXVIIXXVIII; Cf. Sebastião Tavares de Pinho. Humanismo em Portugal, Estudos I. Lisboa: Imprensa Nacional - Casa da Moeda, 2006, pp. 107-108

${ }^{16} \mathrm{Vd}$. Aires Barbosa. Aratoris Cardinalis..., fol. cii vo. 
noutra parte e tentarão atacá-la com trágulas ou seguramente retê-la com o lançamento de arpéus, pois é provavelmente com dardos deste tipo que eles vão aparecer-nos pela frente": Sed uiolenti praedones hinc repulsi alia parte ratem nostram quatient, et uel tragulis eam tentabunt infestare, uel certe immissis harpagonibus retinere. Nam huiusmodi telis nobis forsan obuiabunt. ${ }^{17}$

Porém o derradeiro e mais violento ataque contra o nosso humanista é movido pelos teólogos, que, não tendo argumentos científicos contra a sua obra filológica, em que ele mostra dominar as próprias questões de matéria teológica que a Historia Apostolica de Arátor naturalmente lhe suscita, entrando assim na seara dos mestres da ciência sacra, lançam-lhe uma ridícula condenação que ele rejeita e expõe desta maneira, sempre apoiado na metáfora náutica:

Sed hinc reiecti oppugnatores mei se hactenus missilibus et leuibus iaculis mecum egisse contendent. At nunc tormento aliquo fulmineo et proeliari machina nostrae rati suppressionem ac naufragium minabuntur. Itaque dicent: "Quid homini connubii uinculis alligato cum theologia?" Et quasi diuinae litterae in cucullato habitu aut in sacerdotis pallio tantum sedeant, "cur» inquient «res sacras profanae manus contrectant et polluunt? Non enim decet uos qui mariti estis, sed sacris initiatos diuina scientia.»

"Mas os meus agressores, daqui repelidos, afirmarão que até este momento lidaram comigo com armas de arremesso e dardos ligeiros. Agora, porém, ameaçarão o afundamento e naufrágio da nossa barca com o recurso a algum arremesso de fogo e máquina de guerra. E, assim, dirão: «Que tem a ver com a Teologia um homem amarrado às cadeias do matrimónio?» E, como se as divinas letras assentassem apenas num hábito com capuz ou numa capa de sacerdote, dirão: «Por que razão mãos profanas tocam e mancham as coisas sagradas? A ciência divina não é própria de vós que sois maridos, mas dos iniciados nas coisas sacras."

E Aires Barbosa acrescenta com ironia, voltando à metáfora náutica dos piratas e salteadores do mar, insinuando que ele, na sua humilde ciência teológica, talvez mereça melhor do que eles ornar a sua cabeça com as insígnias doutorais dessa prestigiada faculdade:

Vtinam (ut ad uos redeam, auditores amantissimi) piratae uel potius canes illi non tam falsum quam uerum mibi crimen oblatrarent, et ego non imus sed summus theologus essem, ut possem capiti meo dominae coronam iure circumponere. ${ }^{18}$

\footnotetext{
${ }^{17}$ Vd. Aires Barbosa. Aratoris Cardinalis..., fol. cii vo.
}

${ }^{18}$ Vd. Aires Barbosa. Aratoris Cardinalis..., fol. ciii. 
"Quem dera (para me dirigir de novo a vós, amabilíssimos ouvintes) que os piratas, ou antes, aqueles cães ladrassem contra mim acusando-me não tanto de um crime falso mas verdadeiro, e que eu fosse não um ínfimo mas um supremo perito de teologia, para poder com razão circundar a minha cabeça com a coroa dessa Senhora."

E o humanista acaba por rebater e votar ao desprezo os adversários e termina o prefácio do Livro II com uma nova invocação a Deus e à Virgem, para que o inspirem e ajudem a levar esta segunda parte da empresa literária até ao fim, repetindo mais uma vez a metáfora náutica ${ }^{19}$ :

Et nunc, omnipotens, quamuis iuuenilia tractem, precor inspires uento mea uela secundo!

Tu quoque, Virgo Parens, da, clementissima Virgo, ut sit grata uiris mea commentatio doctis.

"E agora, Deus omnipotente, ainda que eu trate de juvenílias, dignai-Vos enfunar as minhas velas com vento favorável! E também Vós, Ó Virgem Mãe, concedei-me, clementíssima Virgem, Que o meu comentário seja agradável aos homens doutos.”

Finalmente, terminado o comentário do Livro II, num total de 1.250 versos distribuídos por dezanove secções sobre os feitos do apóstolo Paulo, Aires Barbosa dá por finda a sua viagem literária com a chegada ao porto do seu destino, e assim conclui esta edição comentada da Historia Apostolica do poeta cardeal Arátor:

Sed quoniam iam in portum caelesti flante spiritu peruecti sumus, uela complicemus, nauem subducamus eique gratias agamus cuius munere nostrae commentationis munera uobis impartiri, auditores suauissimi, datum est. Erimus autem gratiores magisque accepti a Deo clementissimo beneficii memores, si nobis in mentem crebro uenerit recordatione assidua recolentibus, quantum fuerit tot scopulos, tot maria, tot turbines euasisse, mediosque uiam per hostes tenuisse. Ad hunc autem optatae quietis sinum licuisset nunquam nobis uenire sine Dei fauore, qui dixit: "Sine me nibil potestis facere ${ }^{20}$

Proderit sane repetere memoria casus uarios et pericula et laborem, quae tam et si in experiendo dura fuerunt tamen in recordando ei iucunda sunt, qui extra aleam discriminis positus secure in portu quiescit. ${ }^{21}$

\footnotetext{
${ }^{19} \mathrm{Vd}$. Aires Barbosa. Aratoris Cardinalis..., fol. ciiii vo.

${ }^{20}$ Vd. Aires Barbosa. Aratoris Cardinalis..., fol. cxlviii vo - cxlviiii, mihi fol. cxlviiii vo - cl.

${ }^{21}$ Vd. Aires Barbosa. Aratoris Cardinalis..., fol. cxlviiii, mihi fol. cl.
} 
"Mas, uma vez que já fomos conduzidos ao porto pelo impulso do sopro divino, enrolemos as velas, ponhamos a nau a seco e demos graças Àquele por cujo benefício vos foi concedido, amabilíssimos ouvintes, partilhar dos benefícios do nosso comentário. E com a recordação dessa graça, seremos mais gratos e mais aceites a Deus clementíssimo, se nos vier à mente, em assídua relembrança, quanto nos custou escapar-nos a tantos escolhos, a tantos mares, a tantos turbilhões, e manter a rota pelo meio dos inimigos. E nunca nos teria sido possível chegar a esta baía da almejada tranquilidade sem o favor de Deus, que disse "Sem mim nada podeis fazer.

"De grande proveito será certamente trazer à memória as desvairadas desgraças e perigos e trabalhos que, por muito duros que tenham sido na sua experiência, se tornam todavia agradáveis na recordação de quem, posto já fora do risco de perigo, goza, em segurança, o porto da tranquilidade.”

Em harmonia com o metaforismo náutico que percorre esta obra de Aires Barbosa, e a confirmá-lo, o humanista fez publicar à cabeça da sua edição o seguinte epigrama dedicado ao leitor comum e dominado pela mesma metáfora, da autoria de um seu aluno chamado Teófilo, que relembra a origem portuguesa do seu mestre e a sua função de professor que lhe valera o apelido de "Mestre Grego", e esta sua aventura de marinheiro-escritor ${ }^{22}$ :

\section{Theophilvs AD Lectorem de Nova COMMENTATIONE}

Arit LVSITANi PRAECEPTORIS SVI.

Primus in undoso quisquis dare uela profundo est

Vsus, et ignotas sollicitare uias,

Naturam ingenio uicit. Namque astra secutus

Subdidit imperio caerula cuncta suo;

Terruit haud illum Caelum undique et undique pontus,

Atque suo aspectu terra relicta procul.

Arduus haud illi decimae tumor obstitit undae

Haud breuia, et Syrtes, Cyaneaeue petrae.

Quin raperet solis patuit quod piscibus aequor.

Artis, an audendi, laus prior utra fuit?

Qui minus ecce ualet, cui Lusitania origo est,

Cui Graeco nomen Graecia culta dedit?

Publica demisit praeclara audacia nostri

Barbosae celebris doctiloquique uiri.

Deseruit terras, fructusque ingressus, Arator

Docte, tuos, fluctus et uada salsa domat.

Atrum occurrebat picea caligine caelum,

Horrebantque feri monstra profunda maris.

${ }^{22}$ Vd. Aires Barbosa. Aratoris Cardinalis..., fol. i. 
Omnia felici cursu peragrauit, et undas

Intactasque docet findere primus aquas.

Monstrat et ingenio quod nullus transiit aequor,

Id transire queat qua ratione puer.

Telos.

\section{TEÓfILO, AO LEITOR, ACERCA DO RECENTE COMENTÁRIO do seu mestre Aires Barbosa}

Quem quer que tenha ousado largar vela nas ondas

Do profundo e acossar seus ignotos caminhos

Venceu com seu engenho a natureza. Pois, ao seguir os astros,

Submeteu ao seu império todos os seres celestes;

Não o assustou aquele céu de todo o lado, aquele mar em toda a volta,

Nem a terra deixada ao longe e fora de sua vista.

Não lhe resistiu o alto mar inchado na sua décima onda,

Nem baixios, nem Sirtes, nem Rochedos Ciâneos.

Quem acaso se arrogaria o que só aos peixes o mar patenteou,

Ou quem primeiro teve a honra da arte de ousar uma e outra coisa?

Eis, foi quem menos poder tem, quem tem Lusitânia por origem,

Ao qual, como a um grego, a Grécia o seu nome concedeu!

Largou excelências públicas a audácia do nosso

Homem famoso e bem-falante Barbosa.

Saiu da terra e, entrando nas tuas vagas, ó douto

Arátor, as vagas e as salsas ondas domina.

Vinha contra ele o céu escurecido de negra caligem;

Erguiam-se, pavorosos, os profundos monstros do fero mar.

Tudo ele atravessou em seu fecundo percurso; e é quem

Primeiro ensina a rasgar as vagas e ondas intactas.

E mostra com seu talento que nenhum oceano o superou,

$\mathrm{E}$ com que processo o pode superar uma criança.

Este recurso ao espaço e à vida da navegação como termo comparativo e simbólico quer da existência humana, da experiência amorosa, da atividade política e sobretudo da criação literária, fazendo do ser humano, do enamorado, do Estado ou de quem o governa, e em particular do criador literário, navegantes de outros tantos mares em que lutam pelo seu destino, este recurso - repito representa, como vimos, uma herança antiga de origem greco-latina e manteve uma forte e perene tradição nas sucessivas épocas e literaturas, designadamente na Idade Média e no Renascimento. A prová-lo, podemos lembrar Dante nos séculos XIII-XIV, que recorre à bela imagem da nau do engenho literário, por exemplo, no início do segundo livro do Convívio e no começo tanto do 
Purgatório (I, 1 sqq.), como do Paraíso (II, 1-15) da Divina Comédia ${ }^{23}$; e, já no séc. XVI, Ariosto, que usa do mesmo recurso no canto 46 de Orlando Furioso ${ }^{24}$, bem como o teorizador Marco Jerónimo Vida na sua Arte Poética, I, 62-65 e 80-81 $1^{25}$.

No domínio da área política e social ficou famosa a grande alegoria do estraburguês Sebastião Brant, A Nau dos Loucos [Das Narrenschiff(1494); trad. latina Stultifera Nauis (1497), por Jacob Locher), em que o autor satiriza as fraquezas e desvarios da sociedade do seu tempo. E no campo da lírica amorosa, entre muitos exemplos citarei o curioso exemplo quinhentista do humanista flamengo Everaerst, mais conhecido por João Segundo, que num poema dos seus Basia (I, 9-12), exprime a sua paixão pela amada Júlia no contexto de uma travessia náutica pela região dos mortos da tradição clássica ${ }^{26}$.

Quanto à presença desta metáfora náutica em autores portugueses, tanto em língua latina como em português, podemos citar a mero título de exemplo, o Livro da Virtuosa Benfeitoria da coautoria do Infante D. Pedro e frei João Verba (primeira metade do séc. $\mathrm{XV}$ ), em que o(s) autor(es), à beira de terminar a sua composição (no início do "vio e postumeyro livro"), assim se exprime(m): [...] "Nom sento folgança em o que screvi senom emquanto sguardo com pequeno prazer a deleytosa praya daqueste mar grande, que a outros mais sabedores he pequeno ryo. E com sperança de pousar a nave do meu fraco entender que, per batimentos de contrayras ondas, jaz muito fraca em grande cansaço, farey termho em aqueste livro e lançarey ancora sobre o porto, com entençom de tarde ou nunca tornar a logar em que me feyram taaes tempestades." D. Pedro, um escritor arrependido!

Recordemos, também, o italiano ao serviço do Estado e do Humanismo português, Cataldo Parísio Sículo, que inicia o seu poema latino sobre a conquista de Arzila (Arcitinge) com estes versos dedicados a D. João II, antes de $1495^{27}$ :

${ }^{23}$ Cit. por Ernest Robert Curtius. Literatura Européia e Idade Média Latina. Trad. Teodoro Cabral Rónai. São Paulo: Editora Hucitec / Editora da Universidade de São Paulo, 1996, pp. 177-181.

${ }^{24} \mathrm{Cf}$. ibidem.

${ }^{25}$ Cf. Marco Jerónimo Vida. Arte Poética. Introdução, tradução e notas de Arnaldo M. Espírito Santo. Lisboa: Centro de Estudos Clássicos da Universidade de Lisboa, 1990, pp. 144145.

${ }^{26}$ Cf. José Ignacio Ciruelo Borge. Ioannis Secundi, Basia, I, 9-12. Nota para la historiografía literaria de la metáfora náutica. Humanismo y Pervivencia del Mundo Clásico, I. 1. Cádiz: Instituto de Estudios Turolenses / Servicio de Publicaciones de la Universidad de Cádiz, 1993, pp. 323327.

${ }^{27}$ Tradução de Américo da Costa Ramalho. Latim Renascentista em Portugal (Antologia). Coimbra: Centro de Estudos Clássicos e Humanísticos da Universidade de Coimbra, 1985, pp. 64-65. 
Magne deum cultor placido me conspice uultu

Et timidae aspira felici flamine cymbae!

"Grande cultor dos deuses, olha-me com rosto sereno

E com um sopro ameno favorece o meu tímido barco!”

André de Resende termina o seu poema de encómio à cidade e à Universidade de Lovaina, publicado em Bolonha em 1529, incitando a juventude lovaniense a remar a fundo por sobre os mares contra a barbárie dos inimigos da cultura ${ }^{28}$.

D. Jerónimo Osório, no tratado acerca da glória (De gloria libri $V$ ) publicado em Coimbra em 1549, por várias vezes recorre ao comparante da viagem náutica, para exprimir ou o processo da elaboração literária e da discussão filosófica, ou a ambição da vida humana, instável e efémera como um barco à deriva das vagas, ou ainda a conquista da própria glória ${ }^{29}$.

José de Anchieta, ao celebrar, no Brasil, os feitos gloriosos do terceiro governador do Brasil, consignados na sua epopeia De Gestis Mendi de Saa, publicada em Coimbra em 1563, assim cantava ${ }^{30}$ :

[...] Vellem si stringere singula uersu quae facit, ardenti Christi inflammatus amore, immensus foret iste labor, pelagique profundo magna prius paruam mersaret sarcina cymbam, quam posset tuti contingere litora portus, verba prius certis pedibus cogenda deessent, quam memorandarum latissima copia rerum.

Se eu quisesse reduzir a verso quantos feitos Ele praticou, inflamado do ardente amor de Cristo, seria tal tarefa desmedida, e às profundezas do pélago, a enorme carga faria mergulhar o meu pequenino batel, antes que ele pudesse atingir a praia do porto seguro.

E mais faltariam palavras a condensar no rigor do ritmo Do que larguíssima cópia de gestas a celebrar.

\footnotetext{
${ }^{28} \mathrm{Cf}$. André de Resende. Encomium urbis et academiae Lovaniensis. Bolonha, 1529, vv. 171173.

${ }^{29}$ Cf. João Nunes Torrão. D. Jerónimo Osório e o tratado De Gloria, Tomo II. Edição crítica. Coimbra: Faculdade de Letras, 1991, pp. 177, 180-181 e 202.

${ }^{30}$ Vd. José de Anchieta. De gestis Mendi de Saa. Poema Épico. Obras Completas - 10 Volume. Introdução, versão e notas do Pe. Armando Cardoso, S.J., São Paulo: Edições Loyola, 1986, p. 150, vv.1334-1340.
} 
Damião de Góis, em 1566, ao assumir o encargo de escrever a Coroniqua do Felicíssimo Rey Dom Manuel, faz uso da metáfora náutica para exprimir a decisão de deixar outros trabalhos e dar prioridade a essa empresa: "E pois tudo o tratado nesta parte, é quási nada em comparação do que deve ser, voltarei daqui a vela, pera poer a proa nesta." ${ }^{31}$

Camões não podia, evidentemente, deixar de incluir no seu vastíssimo repertório de recursos ao metaforismo clássico, esta imagem da navegação pelos mares da criação literária. $\mathrm{E}$, assim, ao narrar a visita do Catual a bordo da nau capitaina e quando principiava a descrever e a explicar ao visitante, pela boca de Paulo da Gama, o significado das figuras pintadas nas bandeiras, interrompe a descrição da primeira figura - a "de um velho branco, aspeito soberano" que tinha "um ramo por insígnia na dereita" - e faz a seguinte invocação para assinalar a importância deste episódio ${ }^{32}$ :

"Um ramo na mão tinha ... Mas, ó cego,

$\mathrm{Eu}$, que cometo, insano e temerário,

Sem vós, Ninfas do Tejo e do Mondego,

Por caminho tão árduo, longo e vário!

Vosso favor invoco, que navego

Por alto mar, com vento tão contrário,

Que, se não me ajudais, hei grande medo

Que o meu fraco batel se alague cedo.

E não deixa de ser particularmente expressivo o uso camoniano da mesma metáfora náutica no soneto Busque amor novas artes, novo engenho, em que o poeta resume o desconcerto e a desesperança do enamorado nestas palavras de um simples verso: "Andando em bravo mar perdido o lenho".

A mistura da invocação com a metáfora náutica é muito frequente em textos épicos ou de feição similar, como acontece também com o poema acerca da velhice (De senectute) do médico Lopo Serrão, publicado sete anos depois d'Os Lusíadas e num modelo de composição que ostenta amplitude e estrutura de epopeia. Dividido em catorze cantos, num total de cerca de 8000 versos elegíacos, assim começa a sua invocação inicial associada à metáfora da viagem marítima ${ }^{33}$ :

\footnotetext{
Alma Dei Genetrix, supplex tua numina posco, nauiget ut felix haec mea cumba mari.

Tu uero, aligeri regina puerpera coetus, uela senectutis flamine tende tuo.
}

${ }^{31}$ Vd. Damião de Góis. Crónica do Felicissimo Rei Dom Manuel. Nova edição conforme a primeira de 1566. Coimbra: Universidade, 1949, p. 1.

${ }^{32}$ Vd. Luís de Camões. Os Lusíadas. Lisboa: António Gonçalves, 1572, VII, 78.

${ }^{33}$ Vd. Sebastião Tavares de Pinho. Lopo Serrão e o poema Da Velhice, I, 1-7, p. 293. 
Doce Mãe de Deus, suplicante imploro o teu poder,

Para que esta minha barca seja feliz na travessia do mar.

Sê tu, mãe e rainha do coro alado,

A estender, com tua brisa, as velas da velhice.

O mesmo poeta apresenta ao longo do poema vários exemplos da metáfora da nau ou do pélago da vida humana, designadamente em I, 71, V, 295-296; VI, 255-259; e VII, 73-80. E o seu fecho contém o seguinte remate a confirmar a aplicação da mesma metáfora à composição e escrita de todo o poema ${ }^{34}$ :

Cogere uela licet, dum nauis litora pulsat, et licet optatas calce subire domos.

Hoc opus absoluit felici carmine Musa, parta quies ergo limina nostra beet.

É tempo de recolher as velas enquanto a barca bate na praia; É tempo de penetrar, ao fim da meta, nas apetecidas mansões.

Este poema, fechou-o a Musa com um canto auspicioso:

Que o repouso alcançado torne, pois, feliz a nossa morada.

Exemplos como estes podem encontrar-se em muitos outros autores do espaço da língua portuguesa, mas esta amostragem basta para verificar que se trata de um processo literário de frequente recurso e de efeito estético de forte expressividade, embora um tanto esquecido da crítica literária moderna. De longa tradição nas literaturas grega e latina, cujos povos sempre mantiveram grande convivência e dialética com a vida do mar, foi, por isso, um elemento da arte literária de geração natural e por assim dizer espontânea. $\mathrm{E}$ foi assim que o recebemos juntamente com as bases também greco-latinas da nossa cultura lusófona, plasmada numa história também de nautas e navegadores e numa vocação marítima particularmente sensível às imagens do mar.

\footnotetext{
${ }^{34}$ Vd. ibidem, XIV,629-632, p. 738.
} 